\title{
PERAN BELANJA MODAL PADA INFRASTRUKTUR JALAN TERHADAP PERTUMBUHAN EKONOMI DI KABUPATEN SLEMAN
}

\section{(THE ROLE OF ROAD INFRASTRUCTURE EXPENDITURE ON ECONOMIC GROWTH IN SLEMAN DISTRICT)}

\author{
Syavitri S. Utami Rambe*, Doddy Aditya Iskandar** \\ *Mahasiswa Magister Perencanaan Wilayah dan Kota, Universitas Gadjah Mada \\ Jl. Grafika No.2, Senolowo, Sinduadi, Kec. Mlati, Kabupaten Sleman, \\ Daerah Istimewa Yogyakarta 55281 \\ Email: ami.syavitri@gmail.com \\ ** Dosen Magister Perencanaan Wilayah dan Kota, Universitas Gadjah Mada \\ Jl. Grafika No.2, Senolowo, Sinduadi, Kec. Mlati, Kabupaten Sleman, \\ Daerah Istimewa Yogyakarta 55281
}

Diterima: 18 Mei 2021; Direvisi: 3 Agustus 2021; Disetujui: 4 Agustus 2021

\begin{abstract}
ABSTRAK
Tujuan adanya penelttian ini untuk mengukur peran investasi infrastruktur publik kewenangan kabupaten/daerah dalam bentuk jalan yang dilakukan oleh pemerintah daerah terhadap pertumbuhan ekonomi di Kabupaten Sleman. Metode yang digunakan adalah Ordinary Least Square (OLS) dengan teknik Regresi Linier Berganda dan bantuan aplikasi Eviews. Sebelum dilakukan perhitungan dengan regresi linier berganda dilakukan terlebih dahulu uji asumsi klasik yaitu multikolinieritas, heteroskedastisitas, autokorelasi, dan normalitas. Setelah memenuhi keempat uji tersebut dilakukanlah perhitungan regresi dengan memakai persamaan Coub-Douglas Y= A.K.L, dimana Y (laju pertumbuhan ekonomi), A (jumlah panjang jalan kewenangan kabupaten), $\mathrm{K}$ (belanja modal yang dikeluarkan untuk program jalan). L (jumlah angkatan kerja). Berdasarkan hasil perhitungan regresi linier berganda dapat diketahui bahwa variabel $\mathrm{A}, \mathrm{K}$, dan L tersebut secara serentak tidak berpengaruh terhadap $\mathrm{Y}$ karena memiliki nilai $\mathrm{P}$ value $\mathrm{F} 0,582>0,05$ dan nilai $\mathrm{P}$ value $\mathrm{t}$ tiap-tiap variable $>0,05$, serta memiliki nilai Adjusted $\mathrm{R}^{2}$ negatif $(-0,103)$. Hal ini berarti adanya infrastruktur jalan dengan kewenangan kabupaten di Sleman tidak berpengaruh langsung secara signifikan terhadap peningkatan laju pertumbuhan ekonomi. Hal ini dapat terjadi karena faktor lain diluar penelitian yang berpengaruh kuat terhadap Y, seperti keberadaan dan aktivitas pergerakan di jalan protokol yang lebih dominan dan adanya wilayah yang berpotensi mengalami bencana alam. Maka dari itu diperlukan pemetaan potensi di tiap-tiap kecamatan dan pengembangan inovasi sesuai dengan sumber daya alam dan sumber daya manusia yang ada di wilayah sehingga infrastruktur jalan yang tersedia dapat bermanfaat secara maksimal.
\end{abstract}

Kata kunci: Belanja modal; Infrastruktur jalan; Pertumbuhan ekonomi.

\begin{abstract}
The aim of this study is to measure the role of public infrastructure investment in the regions in the form of roads with the authority of local government on economic growth in Sleman Regency. The method used is Ordinary Least Square (OLS) with Multiple Linear Regression techniques and using Eviews application. Before calculating with linear regression, classical assumptions test were needed to do such as multicollinearity, heteroscedasticity, autocorrelation, and normality. After fulfilling these four tests, a regression calculation is performed using the Coub-Douglas equation $Y$ $=$ A.K.L, where $Y$ (economic growth), A (total length of district authority roads), $K$ (capital expenditures issued for road programs). $L$ (number of labor force). Based on the results of multiple linear regression calculations, it can be seen that the variables $A, K$, and $L$ simultaneously have no effect on $Y$ because they have amount of $P$ value for $F$ test $0.582>0.05$ and amount of $P$ value for $t$ test show that each independent variable $>0.05$, and has a negative Adjusted $R^{2}$ value $(-0.103)$.
\end{abstract}


This means that road infrastructure under the authority of the regency in Sleman has no significant effect on increasing the rate of economic growth. This can occur due to other factors outside the research that have a strong influence on $Y$, such as the presence and movement of activities on the more dominant protocol roads and the existence of areas potentially have natural disasters experience. Therefore, it is necessary to map the potential in each sub-district and develop innovations in accordance with the natural and human resources in the area so that the available road infrastructure can be maximally utilized.

Keywords: Capital Expenditure; Road Infrastructure; Economic growth

\section{PENDAHULUAN}

Wilayah merupakan suatu sistem hierarki dari pusat kota. Christaller (1933) dan Losch (1954) menjelaskan bahwa setiap wilayah memiliki urutan perbedaan dari kota besar ke kota kecil (Dawkins, 2003). Perbedaan tersebut berasal dari keanekaragaman barang yang ditawarkan di dalam kota. Wilayah juga identik dengan istilah pasar tenaga kerja yang saling bergantung secara spasial atau disebut Nodal. Hoover dan Giarratani (1985) membagi Nodal menjadi dua karakteristik yaitu, (1) terintegrasi secara internal fungsional sampai pada arus tenaga kerja, modal, atau komoditas yang lebih sering terjadi di dalam wilayah dibandingkan ke wilayah lain. (2) Di dalam wilayah terdapat kegiatan berbasis pada satu titik atau simpul dimana diduga terdapat suatu dominasi (Dawkins, 2003).

Suatu wilayah dapat dikatakan tumbuh apabila mampu menyediakan kebutuhan barang dan jasa kepada masyarakat sehingga memungkinkan untuk terjadi peningkatan standar hidup serta penurunan tingkat pengangguran dalam jangka panjang. Keberadaan infrastruktur kerap kali dijadikan salah satu tolak ukur untuk meningkatkan pertumbuhan ekonomi suatu wilayah. World Bank (1994:12) membagi infrastruktur menjadi tiga, yaitu (1) infrastruktur ekonomi (pembangunan fisik penunjang aktivitas ekonomi seperti air, sanitasi, listrik, telkom, dan gas), pekerjaan umum (jalan, jembatan, bendungan, irigasi, drainase), dan sektor transportasi (jalan, rel, dsb). (2) infrastruktur sosial (mengarah pada pembangunan manusia dan lingkungannya meliputi perumahan, kesehatan (rumah sakit dan pusat kesehatan), pendidikan (sekolah dan perpustakaan), dan rekreasi (taman dan museum). (3) infrastruktur administrasi dan koordinasi meliputi kontrol administrasi dan koordinasi, penegakan hukum, serta kebudayaan. Furie (2006) dalam Snieska dan Simkunaite (2009) menjelaskan bahwa ekonom dan perencana kota membedakan infrastruktur menjadi dua jenis, yaitu (1) infrastruktur ekonomi, merupakan infrastruktur yang dapat mendorong kegiatan ekonomi seperti jalan raya, rel kereta api, bandara, Pelabuhan laut, listrik, telekomunikasi, air bersih, dan sanitasi sementara (2) infrastruktur sosial merupakan infrastruktur yang mempromosikan standar Kesehatan, Pendidikan, maupun budaya (kegiatan yang berdampak langsung maupun tidak langsung terhadap kesejahteraan) seperti sekolah, perpustakaan, universitas, klinik, rumah sakit, pengadilan, museum, teater, taman bermain.

Pada era pemerintahan Presiden Jokowi, terdapat undang-undang tentang otonomi daerah Nomor 23 Tahun 2014 yang mengatur mengenai kewenangan pengelolaan infrastruktur antara pemerintah pusat, provinsi, dan daerah yang membuat pemerintah daerah lebih leluasa dalam mengalokasikan anggarannya untuk berinvestasi khususnya di sektor infrastruktur. Menurut Harrod - Domar dalam Murni (2006:185), adanya investasi mampu menciptakan pertumbuhan yang tangguh atau steady growth dalam suatu perekonomian. Investasi didefinisikan sebagai komitmen sumber daya lain atau sejumlah uang yang dilakukan pada masa saat ini (present time) dengan harapan mendapatkan manfaat di masa mendatang (in future). Peran yang dilakukan pemerintah daerah dalam bentuk investasi ini disebut peran alokatif. Pada peran ini pemerintah memiliki tugas untuk menyusun kebijakan alokasi belanja daerah pada sektorsektor yang dianggap dapat memicu pertumbuhan ekonomi wilayah. Kebijakan tersebut dilakukan berdasarkan klasifikasi ekonomi dalam komposisi belanja modal, belanja pegawai, belanja barang dan jasa, belanja bantuan sosial, serta belanja hibah. Investasi yang dilakukan 
melalui belanja modal mampu berkontribusi secara jangka pendek dan jangka panjang. Kontribusi jangka pendek melalui penyerapan tenaga kerja dan belanja material, sedangkan jangka panjang melalui kolaborasi dan kerjasama dengan sektor swasta.

Kabupaten Sleman merupakan kabupaten yang memiliki letak strategis karena berbatasan langsung dengan Kota Yogyakarta. Terdapat wilayah aglomerasi dampak perkembangan dari perkotaan Yogyakarta di beberapa kecamatan yaitu Kecamatan Mlati, Kecamatan Gamping, serta Kecamatan Depok. Selain itu, terdapat wilayah peri-urban/sub-urban seperti Kecamatan Sleman, Kecamatan Ngaglik, dan Kecamatan Godean, yang berlokasi agak berjauhan dengan Kota Yogyakarta namun potensial untuk berkembang menjadi tujuan kegiatan masyarakat. Kabupaten Sleman juga termasuk dalam wilayah yang memliki jalur ekonomi sebagai penghubung antar kota-kota pelabuhan utama seperti Jakarta, Semarang, serta Surabaya. Hal ini memicu pertumbuhan ekonomi di Kabupaten Sleman menjadi pesat. Jika dilihat dari nilai belanja daerah yang dikeluarkan Kabupaten Sleman pada tahun 2018-2019, angkanya terus mengalami peningkatan khususnya untuk belanja infrastruktur sebesar Rp 322,32 milyar dan Rp 344,72 milyar. Hal ini berarti terdapat kenaikan sebesar 0,06\%. Berdasarkan data BPS, nilai laju pertumbuhan PDRB berdasarkan harga konstan pada tahun 2014-2019 di Kabupaten Sleman lebih tinggi dibandingkan DIY, namun pada tahun 2017-2019 angka pertumbuhannya lebih rendah dibandingkan Kulon Progo. Hal ini berbanding terbalik dengan indeks gini yang ada di Kabupaten Sleman. Berdasarkan nilai indeks gini, Kabupaten Sleman termasuk dalam ketimpangan moderat yang berarti hasil pembangunan yang telah dilakukan oleh pemerintah belum dapat dinikmati oleh penduduk secara merata serta terjadinya ketimpangan antara penduduk yang memiliki penghasilan rendah dengan penduduk yang memiliki penghasilan tinggi.

Susetyo (2018) mengemukakan bahwa keberadaan belanja modal yang dikeluarkan untuk pemenuhan infrastruktur publik belum diprioritaskan untuk mendorong perekonomian lokal, sehingga belum mampu meningkatkan sumber daya manusia dan mengurangi kesenjangan antar daerah. Hasil laporan UNCTAD tentang Trade and Development tahun 2018 pada negara berkembang dan kurang berkembang, menunjukkan investasi pada infrastruktur publik tidak selalu mampu meningkatkan perekonomian dan mencapai kemakmuran yang berkelanjutan. Hal ini dikarenakan ada terlalu banyak penekanan pada infrastruktur sebagai peluang bisnis tanpa diimbangi dengan mengaitkan pembangunan infrastruktur apakah sesuai dan mendukung strategi pembangunan yang lebih luas terutama industrialisasi dan diversifikasi. Berdasarkan hal tersebut tujuan dalam penelitian ini adalah untuk mengukur peran investasi infrastruktur publik dalam bentuk jalan yang dilakukan oleh pemerintah daerah terhadap pertumbuhan ekonomi di Kabupaten Sleman.

\section{METODE}

Teknik pengumpulan data merupakan teknik yang digunakan dalam mendapatkan data pada saat melakukan penelitian. Teknik ini terbagi menjadi dua yaitu survei primer dan survei sekunder. Survei primer yang dilakukan adalah dengan wawancara kepada pihak pemerintah daerah dengan tipe wawancara terbuka. Sedangkan untuk survei sekunder didapatkan dari dinas-dinas terkait meliputi data dasar jalan, asset, dan inventaris jalan, laporan DPA, dan laporan LAKIP. Metode analisis data yang digunakan adalah dengan analisis dekskriptif evaluatif. Analisis deskriptif adalah metode analisis yang digunakan untuk menganalisis data dengan cara mendeskripsikan atau menggambarkan data yang telah terkumpul sebagaimana adanya tanpa bermaksud membuat kesimpulan yang berlaku untuk umum atau generalisasi (Sugiyono, 2014). Pendekatan evaluatif yang dimaksud adalah evaluasi dari kondisi eksisting yang ada dengan kriteria, tolak ukur, serta standar yang digunakan sebagai pembanding.

Penelitian dilakukan di Kabupaten Sleman dengan menggunakan data kurun waktu dari tahun 2015-2020. Teknik analisa yang digunakan adalah dengan konsep Ordinary Least Square 
(OLS) dengan teknik regresi linier berganda dan bantuan aplikasi Eviews. Pada konsep OLS perlu dilakukan uji asumsi klasik yang terdiri dari uji multikolinieritas, uji heteroskedastisitas, uji autokorelasi, dan uji normalitas. Uji tersebut dilakukan agar model estimasi menghasilkan Unbiased Linier Estimator dan memiliki varian minimun Best Linier Unibiased Estimator (BLUE). Persamaan yang digunakan adalah persamaan Coub-Douglas sebagai berikut:

$$
\mathrm{Y}=\mathrm{A} \cdot \mathrm{K} \cdot \mathrm{L} \text {. }
$$

Dimana:

Y : Laju pertumbuhan ekonomi (Persentase)

A : Jumlah Panjang Jalan Kondisi Baik- Rusak Ringan (Meter)

K : Belanja Modal Program Peningkatan dan Pemeliharaan Jalan (Rupiah)

L : Juml pegawai pemerintah daerah lulusan SMA - Sarjana (orang)

Setelah menghasilkan persamaan model regresi linier berganda, kemudian dilakukan Goodness of Fit pada model yang teridiri dari uji statistik F dan $\mathrm{t}$ menggunakan nilai $\mathrm{P}$ value, serta nilai Adjusted $\mathrm{R}^{2}$ untuk mengetahui apakah hasil pemodelan tersebut telah signifikan secara statistik.

\section{HASIL DAN PEMBAHASAN}

Sebelum dilakukan perhitungan dengan regresi linier berganda dilakukan terlebih dahulu uji asumsi klasik. Berikut ini merupakan hasil uji asumsi klasik yang telah dilakukan.

Tabel 1 Uji Asumsi Klasik

\begin{tabular}{|c|c|c|}
\hline Uji & Nilai & Keterangan \\
\hline \multirow[b]{2}{*}{ Multikolinieritas } & Nilai korelasi antar variabel $<0,9$ & \multirow{2}{*}{$\begin{array}{l}\text { "Tidak ada multikolinearitas" yang serius } \\
\text { dalam variabel }\end{array}$} \\
\hline & $\begin{array}{l}\text { Nilai VIF pada masing-masing variabel } \\
<10\end{array}$ & \\
\hline \multirow{3}{*}{ Heteroskedastisitas } & Probabilitas Chi Square & Nilai probabilitas chi Square $>0,05$, \\
\hline & 0,2238 & berarti \\
\hline & & "Tidak ada Heteroskedastisitas" \\
\hline \multirow{3}{*}{ Autokorelasi } & Durbin Watson 1,908 & jika du $<$ dw $<4-$ du menggunakan $\alpha$ \\
\hline & $\begin{array}{l}\text { seningga didapatkan nila1 } \\
\qquad 1,400<1,908<2,600\end{array}$ & $5 \%(0,0 \supset)$ \\
\hline & & "Tidak ada Autokorelasi" \\
\hline Normalitas & $\begin{array}{l}\text { Nilai jarque bera masing-masing variabel } \\
<2\end{array}$ & $\begin{array}{l}\text { Variabel-variabel tersebut "Terdistribusi } \\
\text { Normal". }\end{array}$ \\
\hline
\end{tabular}

Sumber: Analisis Penulis, 2021

Berdasarkan hasil perhitungan regresi linier berganda dengan batuan aplikasi Eviews peran jalan terhadap laju pertumbuhan ekonomi di Kabupaten Sleman didapatkan hasil persamaan model sebagai berikut:

Tabel 2 Hasil Regresi Peran Jalan Terhadap Laju Pertumbuhan Ekonomi di Sleman MODEL $\mathrm{Y}_{\mathrm{LPE}}=4,36.10^{-6}-0,402 \mathrm{~A}+0,772 \mathrm{~K}+0,238 \mathrm{~L}$

\begin{tabular}{|c|c|c|}
\hline MODEL & \multicolumn{2}{|c|}{$\mathrm{Y}_{\mathrm{LPE}}=4,36 \cdot 10^{-6}-0,402 \mathrm{~A}+0,772 \mathrm{~K}+0,238 \mathrm{~L}$} \\
\hline Goodness Of Fit & Nilai & Keterangan \\
\hline$P$ value $F$ & $0,582>0,05$ & $\begin{array}{l}\text { Dilihat dari nilai } \mathrm{F} \text { dan } \mathrm{t} \text { Variabel independen } \\
\mathrm{A}, \mathrm{K}, \mathrm{L} \text { tidak ada pengaruh langsung terhadap } \\
\text { variabel dependen Y. Sedangkan jika dilihat dari nilai }\end{array}$ \\
\hline $\mathrm{P}$ Value $\mathrm{t}$ & $\begin{array}{l}\text { Probabilitas tiap } \\
\text { variabel }>0,05\end{array}$ & 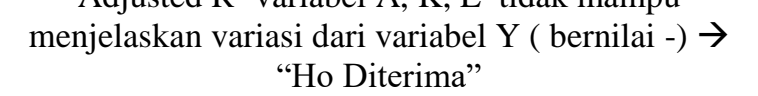 \\
\hline Adjusted $\mathrm{R}^{2}$ & $-0,103$ & \\
\hline
\end{tabular}

Sumber: Analisis Penulis, 2021 
Hasil regresi untuk peran jalan terhadap laju pertumbuhan ekonomi menghasilkan interpretasi sebagai berikut:

1. Apabila dilihat dari nilai Adjusted $\mathrm{R}^{2}$ variabel $\mathrm{Y}_{\mathrm{LPE}}$ tidak dipengaruhi oleh faktor-faktor dalam penelitian ini karena memiliki nilai Adjusted $\mathrm{R}^{2}$ negatif. Ghozali (2017) menyatakan apabila nilai Adjusted $\mathrm{R}^{2}$ negatif maka dianggap bernilai 0 .

2. Ketiga variabel $\mathrm{A}, \mathrm{K}, \mathrm{L}$ secara simultan tidak berpengaruh signifikan terhadap laju pertumbuhan ekonomi.

$$
\mathrm{Y}_{\mathrm{LPE}}=4,36.10^{-6}-0,402 \mathrm{~A}+0,772 \mathrm{~K}+0,238 \mathrm{~L}
$$

3. Variabel $\mathrm{K}$ dan $\mathrm{L}$ sama-sama berpengaruh positif terhadap laju pertumbuhan ekonomi, sedangkan variabel A berpengaruh negatif terhadap laju pertumbuhan ekonomi.

Keberadaan jalan berpengaruh positif dan langsung terhadap variabel modal dan jumlah angkatan kerja serta laju pertumbuhan ekonomi di karenakan:

1. Dalam program pembangunan dan pemeliharaan jalan keberadaan modal menentukan kuantitas dan kualitas infrastruktur jalan yang akan dibangun atau yang akan dilakukan pemeliharaan, sehingga semakin besar jumlah modal yang dikeluarkan maka semakin baik pula kualitas dan kuantitas jalan yang ada. Jalan yang memiliki kualitas yang baik akan mempermudah aksesbilitas orang maupun barang.

2. Sejalan dengan hal tersebut, keberadaan pembangunan dan pemeliharaan infrastruktur jalan dengan modal yang besar berpengaruh terhadap penyediaan lapangan kerja. Adanya pembangunan dan pemeliharaan infrastruktur jalan dapat menyerap tenaga kerja baik pada saat pra kegiatan ataupun pada saat kegiatan program jalan berlangsung.

Sedangkan jika dilihat berdasarkan hasil interpretasi tersebut keberadaan jalan kabupaten mengindikasikan tidak berpengaruh secara langsung dan signifikan terhadap peningkatan laju pertumbuhan ekonomi di Kabupaten Sleman. Hal tersebut dapat terjadi karena dipengaruhi oleh faktor lain di luar penelitian seperti:

1. Pergerakan yang terjadi di jalan kabupaten mayoritas adalah pergerakan lokal dan jalan yang ada hanya menghubungkan antar permukiman

2. Tidak banyak aktivitas komersial yang terjadi pada jalan-jalan kabupaten

3. Adanya potensi bencana alam di beberapa wilayah di Kabupaten Sleman

Berikut merupakan hasil kutipan wawancara dengan pihak Dinas Pertanahan dan Tata Ruang Kabupaten Sleman yang menjelaskan mengenai kondisi wilayah Kabupaten Sleman berpengaruh terhadap pertumbuhan ekonomi:

“...Kabupaten Sleman itu pintu masuk dari berbagai daerah seperti bagian utara Kecamatan Tempel berbatasan dengan Kabupaten Magelang, bagian selatan dengan Kota Yogyakarta, bagian timur dengan Kabupaten Klaten, dan bagian barat dengan Kabupaten Kulon Progo. Jalan-jalan yang dijadikan pintu masuk itu kebanyakan jalan protokol yang kewenangan pusat dan provinsi..." (RW, Wawancara Januari 2021)

Disi lain terdapat pernyataan dari pihak Dinas PU Bina Marga yang menggambarkan pengaruh jalan kabupaten terhadap pertumbuhan ekonomi di Kabupaten Sleman.

“...Kebanyakan Jalan kabupaten di Sleman itu hanya jalan penghubung antar kecamatan atau permukiman, sementara Sleman perlintasan, jadi banyak jalan provinsi atau nasional. Kendaraan yang lewat lebih banyak di 
situ, titik-titik pertumbuhan ekonomi nya juga di sana...". (FM, Wawancara

Januari 2021)

Terdapat beberapa faktor di luar infrastruktur yang mampu mempengaruhi aktivitas produksi dan perkembangan ekonomi wilayah menurut Susetya (2018) salah satunya adalah adanya potensi bencana di satu daerah yang mempengaruhi ketersediaan infrastruktur publik sehingga tingkat pelayanan infrastruktur publik tersebut relatif rendah. Hal ini juga didukung olen hasil wawancara dengan pihak BAPPEDA yang menyebutkan

“...wilayah utara Kabupaten Sleman itu sudah rumayan berkembang, tapi karna ada potensi bencana alam yang membuat orang masih suka takut untuk wisata kesana. Makanya pariwisata yang ada masih belum berefek ke perekonmian masyarakat sekitarnya...” (DSG, Wawancara Januari 2021)

Sebayang (2020) juga menjelaskan bahwa dampak adanya infrastruktur bagi pembangunan daerah tidak dapat dirasakan secara langsung manfaatnya, melainkan harus bersamaan dengan adanya kemampuan kewirausahaan di tingkat lokal, iklim usaha daerah, kebijakan pemerintah daerah, serta kondisi sosial budaya. Keberadaan infrastruktur tidak bisa menjadi variabel tunggal untuk mendorong pertumbuhan ekonomi jangka panjang. Infrastruktur hanya sebagai prasyarat dasar yang membutuhkan faktor lain untuk bersama-sama mendorong pertumbuhan ekonomi daerah. Berdasarkan hal tersebut dapat ditarik kesimpulan bahwa keberadaan jalan tidak bisa berdiri sendiri dalam menunjang pertumbuhan ekonomi. Kondisi wilayah di Kabupaten Sleman berpengaruh terhadap peningkatan pertumbuhan ekonomi. Lokasi Kabupaten Sleman yang strategis dan banyak dilewati oleh jalan protokol sangat berpangaruh terhadap pertumbuhan ekonomi. Jalan-jalan protokol tersebut memiliki daya tarik tersendiri sehingga banyak titik pusat perekonomian yang tumbuh. Selain itu jalan protokol menjadi sumber dari pergerakan menerus maupun ulang alik dari wilayah di sekitar Kabupaten Sleman. Berbeda dengan kondisi jalan kabupaten yang belum terdapat iklim usaha untuk memicu timbulnya titik-titik pusat pertumbuhan ekonomi. Maka dari itu keberadaan jalan kabupaten terhadap peningkatan perekonomian di Kabupaten Sleman tidak berpengaruh langsung secara signifikan terhadap laju pertumbuhan ekonomi.

\section{KESIMPULAN}

Berdasarkan hasil perhitungan regresi didapatkan model persamaan $\mathrm{Y}_{\mathrm{LPE}}=4,36.10^{-6}$ $0,402 \mathrm{~A}+0,772 \mathrm{~K}+0,238 \mathrm{~L}$ dengan nilai Adjusted $\mathrm{R}^{2}-0,103$ dan nilai $\mathrm{P}$ value $\mathrm{F}$ dan $\mathrm{P}$ value $\mathrm{t}$ $>0,05$. Hal ini berarti keberadaan infrastruktur jalan dengan kewenangan kabupaten tidak berpengaruh langsung dan signifikan terhadap laju pertumbuhan ekonomi di Sleman serta variabel A (jumlah panjang jalan), K (belanja modal program jalan), L (angkatan kerja) secara simultan tidak berpengaruh signifikan terhadap Y (laju pertumbuhan ekonomi). Berdasarkan ulasan teori maupun hasil penelitian dapat disimpulkan bahwa investasi fisik pada infrastruktur jalan dalam bentuk belanja modal yang ada di Kabupaten Sleman bermanfaat namun tidak berpengaruh secara langsung dalam mendongkrak perkembangan wilayah. Keberadaan jalan kabupaten tersebut belum berpengaruh secara signifikan dalam meningkatkan laju pertumbuhan ekonomi di Kabupaten Sleman. Hal ini disebabkan dalam proses pembangunan infrastruktur di Kabupaten Sleman masih membutuhkan tahapan baru (inovasi) agar mampu bersaing membentuk suatu pertumbuhan ekonomi yang kuat dan merata di tiap-tiap kecamatan.

\section{REKOMENDASI}

Adapun rekomendasi yang dapat diberikan peneliti untuk pemerintah daerah yaitu:

1. Perlunya pemetaan potensi dan masalah di tiap-tiap kecamatan serta pemetaan kondisi infrastruktur jalan dengan kewenangan kabupaten agar pemerintah daerah dapat 
merencanakan dan mensinergikan pembangunan infrastruktur jalan sesuai dengan kemampuan SDA dan SDM yang ada.

2. Perlunya pengembangan sistem yang menunjang untuk pendataan mengenai kondisi infrastruktur jalan, jumlah infrastruktur jalan, lokasi infrastruktur jalan dengan kewenangan pemerintah daerah, sehingga memudahkan masyarakat dan pemerintah dalam melakukan evaluasi dan monitoring.

3. Perlunya inovasi untuk pengembangan daerah dari pemerintah dalam memanfaatkan infrastruktur jalan menjadi sumber kemakmuran, agar infrastruktur jalan yang telah tersedia mampu dimanfaatkan secara maksimal dan menghasilkan keuntungan.

Diharapkan dengan hal-hal tersebut keberadaan infrasttruktur yang direncanakan ataupun yang telah ada mampu meningkatkan pertumbuhan ekonomi di Kabupaten Sleman serta tiaptiap kecamatan yang ada di Kabupaten Sleman mampu berkembang secara ekonomi, menjadi lebih mandiri, dan dalam jangka panjang mampu mengurangi kemiskinan serta disparitas.

Selain rekomendasi untuk pemerintah daerah, adapula rekomendasi yang ditujukan untuk penulis selanjutnya karena penelititan ini merupakan bentuk identifikasi awal terhadap dampak infrastruktur kewenangan kabupaten khususnya infrastruktur jalan terhadap pertumbuhan ekonomi di Kabupaten Sleman. Terdapat beberapa faktor di luar penelitian ini yang dianggap berpengaruh terhadap perkembangan wilayah yaitu:

1. Memasukkan atau mempertimbangkan faktor geografis wilayah yang ada karena terdapat perbedaan potensi ataupun aktivitas tiap-tiap kecamatan di dalam satu kabupaten.

2. Memasukkan atau mempertimbangkan faktor lokasi infrastruktur dalam perhitungan atau penilaian.

3. Selain itu, diharapkan untuk penelitian selanjutnya melakukan perhitungan menggunakan data pasca kegiatan dengan jangka waktu yang lebih dari > lima (5) tahun agar lebih terlihat dan terasa dampak program yang telah dilaksanakan.

\section{DAFTAR PUSTAKA}

Badan Pusat Statistik. (2019). Indikator Kesejahteraan Rakyat Daerah Istimewa Yogyakarta 2019. Badan Pusat Statistik Provinsi Daerah Istimewa Yogyakarta

Dawkins, Casey J. (2003). Regional Development Theory:Conceptual Foundations, Classic Works, and Recent Developments. Journal of Planning Literature. 18(2)

Ghazali dan Ratmono. (2017). Analisis Multivariat dan Ekonometrika (Teori KOnsep dan Aplikasi dengan Eview 10) Edisi Kedua. Semarang: Badan Penerbit Universitas Diponogoro

Murni, Asfia. (2006). Ekonomi Makro. Jakarta: PT. Rafika Aditama.

Republik Indonesia. (2014). Undang-undang Republik Indeonseia No 23 Tahun 2014 tentang Pemerintah Daerah. Lembaran Negara Republik Indonesia Tahun 2014 Nomor 244. Jakarta

Sebayang A. F dan Sebayang L. K. (2020). Infrastructure Investment and Its Impact to Regional Development. Economic Development Analysis Journal. 9(3), 269-280

Snieska V. dan Simkunaite I. (2009). Socio-Economic Impact of Infrastructure Investments. Inzinerine Ekonomika-Engineering Economics. 63(3), 16-25 
Sugiyono. (2014). Metode Penelitian Pendidikan dan Pendekatan Kuantitatif, Kualitatif dan $R \& D$. Bandung : Alfabeta

Susetya, et al. (2018). Impact of Capital Expenditure and Public Utility Customers to Economic Development of District-City in Sumatra-Indonesia. International Journal of Economics and Financial Issues. 8(1), 126-135

Trade and Development Report. (2018). Power, Platforms And The Free Trade Delusion. United Nation. Dari https://unctad.org/webflyer/trade-and-development-report-2018

World Bank. (1994). World Development Report : Infrastructure for Development. Oxford University Press. New York. 


\section{LAMPIRAN}

Tabel 1 Variabel Indikator Perkembangan Wilayah

\begin{tabular}{llcccccc}
\hline \multirow{2}{*}{ No } & \multicolumn{2}{c}{ Indikator } & \multicolumn{7}{c}{ Tahun } \\
\cline { 3 - 8 } & & $\mathbf{2 0 1 4}$ & $\mathbf{2 0 1 5}$ & $\mathbf{2 0 1 6}$ & $\mathbf{2 0 1 7}$ & $\mathbf{2 0 1 8}$ & $\mathbf{2 0 1 9}$ \\
\hline 1 & $\begin{array}{l}\text { Persentase Laju Pertumbuhan } \\
\text { PDRB ADHK Harga Konstan }\end{array}$ & 5,38 & 5,16 & 5,22 & 5,34 & 6,42 & 6,49 \\
\hline 2 & Indeks Pembangunan Manusia & 80,73 & 81,2 & 82,15 & 82,85 & 83,42 & 83,85 \\
\hline 3 & Persentase Tingkat Kemiskinan & 9,50 & 9,46 & 8,21 & 8,13 & 7,65 & 7,41 \\
\hline \multicolumn{2}{l}{ Sumber: Badan Pusat Statistik Kabupaten Sleman, 2014-2019 }
\end{tabular}

Tabel 2 Kondisi Jalan Kabupaten Sleman 2014-2019

\begin{tabular}{clcccccc}
\hline \multirow{2}{*}{ No } & \multirow{2}{*}{ Kondisi } & \multicolumn{7}{c}{ Panjang Jalan (Km) } \\
\cline { 3 - 8 } & & $\mathbf{2 0 1 4}$ & $\mathbf{2 0 1 5}$ & $\mathbf{2 0 1 6}$ & $\mathbf{2 0 1 7}$ & $\mathbf{2 0 1 8}$ & $\mathbf{2 0 1 9}$ \\
\hline 1 & Baik & 360,9 & 379,575 & 364,27 & 372,50 & 374,65 & 467,10 \\
\hline 2 & Sedang & 223,71 & 215,505 & 249,58 & 239,87 & 241,05 & 48,95 \\
\hline 3 & Rusak Ringan & 79,84 & 74,040 & 64,10 & 70,22 & 59,70 & 38,35 \\
\hline 4 & Rusak Berat & 35,05 & 32,380 & 21,56 & 16,91 & 24,10 & 45,10 \\
\hline & Jumlah & $\mathbf{6 9 9 , 5 0}$ & $\mathbf{6 9 9 , 5 0}$ & $\mathbf{6 9 9 , 5 0}$ & $\mathbf{6 9 9 , 5 0}$ & $\mathbf{6 9 9 , 5 0}$ & $\mathbf{6 9 9 , 5 0}$ \\
\hline
\end{tabular}

Sumber: Data Dasar Jalan Bina Marga dan Lakip DPUP, 2014-2019

Tabel 3 Belanja Modal Jalan Kabupaten Sleman Tahun 2014-2019

\begin{tabular}{lcccccc}
\hline \multirow{2}{*}{ Program } & \multicolumn{5}{c}{ Tahun Anggaran } \\
\cline { 2 - 7 } & $\mathbf{2 0 1 4}$ & $\mathbf{2 0 1 5}$ & $\mathbf{2 0 1 6}$ & $\mathbf{2 0 1 7}$ & $\mathbf{2 0 1 8}$ & $\mathbf{2 0 1 9}$ \\
\hline $\begin{array}{l}\text { Peningkatan } \\
\text { Jalan }\end{array}$ & 16.448 .663 .100 & 19.792 .287 .850 & 37.081 .487 .700 & 54.443 .759 .600 & 65.024 .672 .523 & 71.020 .176 .150 \\
\hline $\begin{array}{l}\text { Pemeliharaan } \\
\text { Jalan }\end{array}$ & 24.218 .708 .000 & 27.785 .159 .616 & 46.131 .337 .282 & 70.088 .769 .665 & 39.487 .089 .787 & 25.067 .989 .617 \\
\hline TOTAL & 40.667 .371 .100 & 47.577 .447 .466 & 83.212 .824 .982 & 124.532 .529 .265 & 104.511 .762 .310 & 96.088 .165 .767 \\
\hline \multicolumn{2}{l}{ Sumber: DPA dan LAKIP DPUPKP, 2014-2019 } & & & &
\end{tabular}

Tabel 4 Jumlah Angkatan Kerja Kabupaten Sleman Berdasarkan Tingkat Pendidikan 20142019

\begin{tabular}{lcc}
\hline \multirow{2}{*}{ Tahun } & \multicolumn{2}{c}{ Tingkat Pendidikan } \\
\cline { 2 - 3 } & Diploma & Sarjana \\
\hline 2015 & 44.583 & 73.827 \\
\hline 2016 & 45.649 & 90.878 \\
\hline 2017 & 52.470 & 90.863 \\
\hline 2018 & 2.068 & 2.303 \\
\hline 2019 & 54.495 & 99.707 \\
\hline 2020 & 39.109 & 120.363 \\
\hline TOTAL & $\mathbf{2 3 8 . 3 7 4}$ & $\mathbf{4 7 7 . 9 4 1}$ \\
\hline
\end{tabular}

Sumber: Kabupaten Sleman Dalam Angka, 2014-2020 